\title{
DIAGNÓSTICO DAS ÁREAS DE PRESERVAÇÃO PERMANENTE DE NASCENTES NA ÁREA URBANA DO MUNICÍPIO DE IRATI-PR
}

\author{
Magda Adriana Lozinski ${ }^{1}$, Rafaelo Balbinot ${ }^{2}$, Diego Venâncio ${ }^{3}$, \\ Paulo Costa de Oliveira Filho ${ }^{2}$, Waldir Nagel Schirmer ${ }^{4}$ \\ ${ }^{1} E^{2} g^{a}$. Ambiental, Irati, PR, Brasil - magda.al@hotmail.com \\ ${ }^{2}$ Eng. Florestal, Dr., Depto. Engenharia Ambiental, UNICENTRO, Irati, PR, Brasil - rbalbinot@ yahoo.com.br; \\ paulocostafh@gmail.com \\ ${ }^{3}$ Eng. Ambiental, Mestrando Ciências Florestais, UNICENTRO, Irati, PR, Brasil - diegoluisvenancio@ yahoo.com \\ ${ }^{4}$ Eng. Químico, Dr., Depto. Engenharia Ambiental, UNICENTRO, Irati, PR, Brasil - wanasch@ yahoo.com.br
}

Recebido para publicação: 01/07/2008 - Aceito para publicação: 19/05/2009

\begin{abstract}
Resumo
O avanço tecnológico e o surgimento de novas técnicas e sensores remotos, capazes de gerar imagens de alta resolução espacial e espectral, tornam os diagnósticos ambientais cada dia mais precisos. O presente trabalho tem como objetivo localizar as nascentes e delimitar suas áreas de preservação permanente utilizando imagens orbitais de alta resolução do sensor Quickbird, bem como identificar o uso do solo dessas áreas para confronto com a legislação. A área de estudo foi a bacia do Arroio dos Pereiras, na área urbana do município de Irati, PR. Os resultados demonstraram que todas as nascentes encontram-se de forma irregular de acordo com o código florestal.

Palavras-chave: Diagnóstico ambiental; área de preservação permanente; geoprocessamento; nascentes.
\end{abstract}

\begin{abstract}
Diagnosis of the permanent preservation areas of the springs of a drainage basin located in the urban area in Irati-PR. The technological advance and the sprouting of new techniques and remote sensors, capable to generate images of high resolution spatial and spectral, become the environment diagnosis more precise at each day. The present work has as objective to locate the springs and to delimit its areas of permanent preservation using orbital images of high resolution of the Quickbird sensor, as to well as identify the land use of these areas for confrontation with the legislation. The study area was the basin of the Pereira's stream in the urban area of the City of Irati - PR. The results had demonstrated that all the springs are at illegal form according to the forest law.

Keywords: Environmental diagnosis; permanent preservation area; geothecnologies; water springs.
\end{abstract}

\section{INTRODUÇÃO}

Frente à crise nas reservas de água doce do planeta e sua possível escassez num futuro próximo, a recuperação, manutenção e uso sustentável das bacias hidrográficas colocam-se como um investimento de retorno ambiental, social e econômico garantido a médio e longo prazo, inclusive no que diz respeito ao mercado de carbono, quando considerada a recuperação das áreas de mata ciliar.

Segundo Silva et al. (2006), é preciso passar a identificar a importância da manutenção da qualidade ambiental das bacias para a qualificação urbana referente ao uso sustentável dos recursos naturais, utilizando os benefícios ambientais advindos dessa manutenção, como por exemplo as matas ciliares, que garantem a qualidade da água, evitam o assoreamento de córregos e rios e são significativas como parte integral da administração urbana, inclusive no que se refere à redução de custos com saúde, operações de contenção de deslizamentos e drenagem urbana. Para garantir sua própria sustentabilidade, o crescimento urbano necessita de um planejamento e uso de tecnologias que garantam a continuidade da vida nos rios e dos remanescentes florestais.

Bacia hidrográfica é a unidade fisiográfica limitada por divisores topográficos, que recolhe toda a precipitação e sedimentos de uma determinada área e a drena para um único local, chamado exutório 
(NAGHETTINI, 2006). Pode ser definida também como a área de drenagem ou escoamento superficial das águas que alimentam um curso de água (SANEPAR, 1999). A bacia hidrográfica é individualizada pelos seus divisores topográficos e possui uma rede fluvial de drenagem, composta pelas nascentes, um rio principal e seus afluentes.

As nascentes, ou mananciais, se formam quando o aquífero atinge a superfície e, consequentemente, a água armazenada no subsolo começa a minar, ou seja, propagar-se. As características de uma nascente podem ser influenciadas por diversos fatores, tais como clima, cobertura vegetal, topografia, geologia, bem como tipo, uso e manejo do solo da área em que a nascente se encontra. As nascentes são definidas como o local no qual se inicia um curso de água (rio, ribeirão, córrego), independentemente das dimensões. As nascentes localizam-se em encostas ou depressões do terreno ou ainda no nível de base representado pelo curso d'água local, e podem ser perenes (de fluxo contínuo), temporárias (de fluxo apenas na estação chuvosa) ou ainda efêmeras (quando surgem durante a chuva, permanecendo por apenas alguns dias ou horas).

De acordo com o Código Florestal Brasileiro (BRASIL, 2007), em nascentes (mesmo intermitentes) e olhos d'água, a distância a ser preservada com vegetação natural é de $50 \mathrm{~m}$. No entanto, o que se observa na maioria das vezes é que essa distância não é respeitada, ocasionando a degeneração das nascentes. Diante dessa realidade e da necessidade de conservação dos recursos hídricos, faz-se importante a realização de diagnósticos das condições das Áreas de Preservação Permanente (APPs) das nascentes, no intuito de estabelecer processos adequados para sua preservação e recuperação quando for o caso.

As propostas de ordenamento territorial dos perímetros urbanos devem ser conduzidas com base nos conceitos funcionais de bacia hidrográfica, pois elas têm sido eleitas como unidades básicas de planejamento, pelo fato de que a resultante de toda ação antrópica irá refletir na sua própria área de abrangência (VALÉRIO FILHO et al., 2005).

Em função da melhoria da resolução espacial e, em parte, também da resolução temporal, resultam novas ou aprimoradas opções de aplicações em muitos setores (JENSEN; COWEN, 1999). A classificação através da técnica de segmentação de imagens passa a ser uma opção aos trabalhos de extração de informações de imagens de alta resolução.

Diante disso, o objetivo deste estudo foi aplicar a técnica de classificação por segmentação para o estudo de bacias hidrográficas urbanas e diagnosticar as condições das APPs das nascentes situadas na bacia hidrográfica do Arroio dos Pereiras, a fim de fornecer subsídios para a gestão ambiental dessa bacia. A escolha desse curso d'água advém do fato de suas nascentes encontrarem-se no interior da área urbana de Irati-PR, sofrendo, portanto, forte ação antrópica.

\section{MATERIAL E MÉTODOS}

\section{Caracterização da área de estudo}

O estudo foi desenvolvido na bacia hidrográfica do Arroio dos Pereiras, localizada na área urbana do município de Irati, que se encontra nas coordenadas $25^{\circ} 27^{\prime} 56^{\prime \prime}$ de latitude sul com interseção com o meridiano 50 37'51" de longitude oeste. A classificação climática para o município é Cfb (temperado), segundo a classificação de Köppen, com geadas frequentes no inverno, média máxima de $24,2^{\circ} \mathrm{C}$, média mínima de $11^{\circ} \mathrm{C}$, média mensal de precipitação pluviométrica de $193 \mathrm{~mm}$ e média mensal de umidade relativa do ar de 79,58\% (IRATI, 2007).

O município de Irati está localizado a $150 \mathrm{~km}$ de Curitiba (IRATI, 2007) e encontra-se na subregião dos pinhais, no Segundo Planalto Paranaense. O município tem sua área drenada por três bacias hidrográficas: bacia do rio Ivaí, bacia do rio Tibagi e bacia do rio Iguaçu. A figura 1 apresenta a bacia do Arroio dos Pereiras.

A região de Irati, sul do estado do Paraná, onde se encontra o Arroio dos Pereiras, pertence à bacia dos rios Paraná e Paraguai. Essa bacia possui uma área de drenagem de $1.237 .000 \mathrm{~km}^{2}$, com uma vazão média anual de $15.620 \mathrm{~m}^{3} . \mathrm{s}^{-1}$, e um volume anual de $495 \mathrm{~km}^{3}$. É a segunda maior bacia hidrográfica do planeta (FRIGOLLETO, 2006).

Quanto ao tipo de solos, predominam os Argissolos (Podzólico), Neossolos (Litólico), Cambissolos e Latossolos (EMBRAPA, 1999), em topografia acidentada. 


\section{Análise e mapeamento das áreas}

Com a utilização do mapeamento planialtimétrico da bacia do Arroio dos Pereiras, foi realizado um diagnóstico ao longo do arroio para quantificar as APPs das nascentes pertencentes a essa bacia.

Para a realização da análise da presença de APP nas nascentes, foi utilizada uma imagem do sensor Quickbird a bordo do satélite Quickbird II, de resolução espacial de 0,61 m, que abrange o quadro urbano do município, cedida pela Prefeitura Municipal de Irati. Utilizou-se o programa SPRING versão 4.3.3. (SPRING 1996), para se efetuar a classificação de uso do solo, através da técnica de segmentação com dois parâmetros.

Inicialmente, procedeu-se à criação de um modelo de dados, no qual foi espacializada a área da bacia hidrográfica do Arroio dos Pereiras, em coordenadas planas referentes ao município de Irati no Sistema de Projeção UTM e Datum WGS 84, de acordo com o posicionamento das nascentes obtido junto à Prefeitura de Irati. A seguir, foram compilados e estruturados os seguintes dados como planos de informações em ambiente SIG: o perímetro da bacia hidrográfica, as imagens orbitais de alta resolução, os cursos d'água que formam a bacia hidrográfica e os pontos de localização obtidos em campo que definem o centro das nascentes da bacia.

De posse dos pontos representando as nascentes, foram elaborados os buffers (mapas de distância) de $50 \mathrm{~m}$ de raio, para a definição das áreas a serem segmentadas para posterior classificação do uso do solo (Figura 2). Na sequência, segmentou-se o recorte da imagem Quickbird, utilizando-se valor 100 para o parâmetro "área mínima" de pixel, o que garante a identificação de áreas de 0,61 x 0,61 m $\left(0,3721 \mathrm{~m}^{2}\right)$, e parâmetro de "similaridade" 15 , considerando uma resolução radiométrica de 8 bits (256 tons de cinza). Esses valores foram utilizados após diversos testes variando ambos os parâmetros.
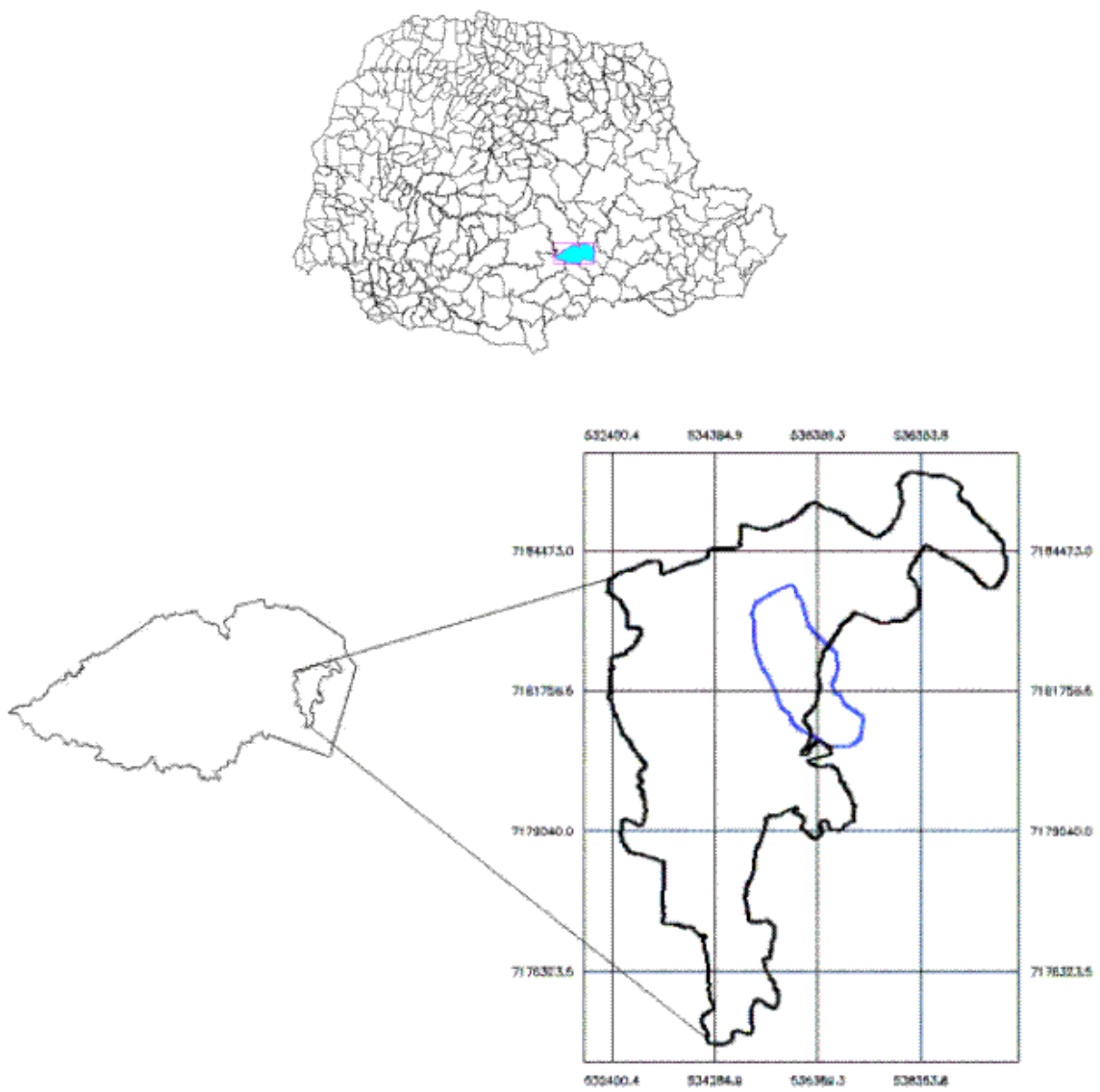

Figura 1. Localização do município de Irati, sua área urbana e a bacia Arroio dos Pereiras. Figure 1. Localization of city of Irati, the urban area and the Pereira's Stream basin. 


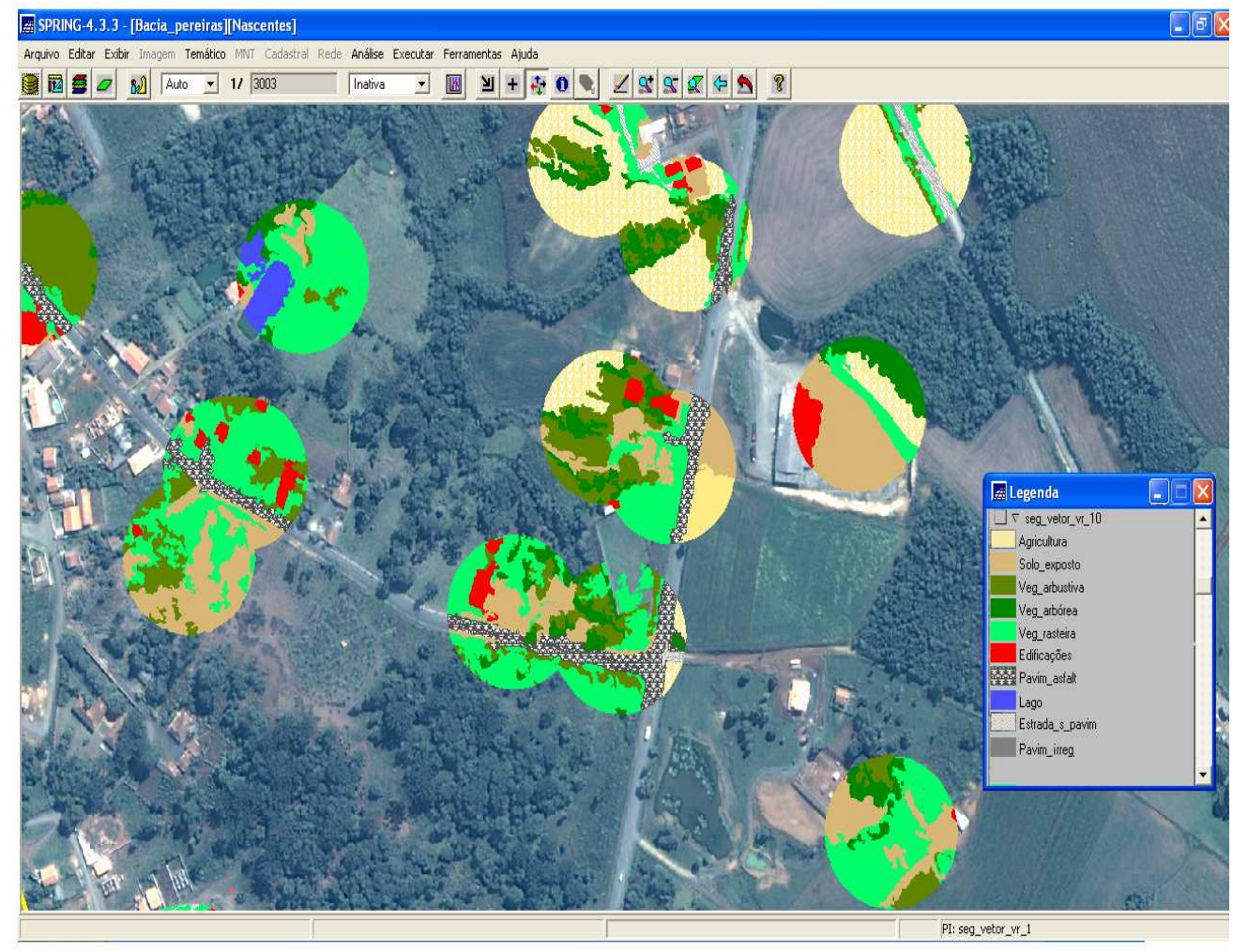

Figura 2. Resultado da classificação por segmentação do raio de abrangência das nascentes sobreposta à composição colorida das bandas de imagem.

Figure 2. Result of the classification by segmentation of the ray of coverage of the springs overlapping to the colorful composition of the image bands.

Em seguida, foi realizada a conversão dos arquivos Raster oriundos da segmentação para arquivo vetorial na APP das nascentes, e posterior edição vetorial desses polígonos.

As seguintes classes de uso do solo encontradas na área de estudo foram definidas através da imagem Quickbird e de trabalho de campo: agricultura, vegetação rasteira, arbustiva e arbórea, estrada sem pavimentação, pavimentação irregular e pavimentação asfáltica, solo exposto, edificações e lagos, totalizando dez classes para o uso e ocupação do solo na APP para cada nascente. A descrição de cada classe de uso ou condição do solo encontra-se na tabela 1.

Tabela 1. Situações de uso do solo e consequente situação legal.

Table 1. Land use situations and consequent legal situation.

\begin{tabular}{lll}
\hline Classe & \multicolumn{1}{c}{ Descrição } & Situação \\
\hline 1- Agricultura & Área com cultivo & Irregular \\
2- Vegetação arbustiva & Com altura superior a 0,50 m e inferior a 4 m & Irregular \\
$3-$ Estrada sem pavimentação & Sem qualquer cobertura impermeabilizante & Irregular \\
$4-$ Edificações & Instalações em alvenaria ou madeira & Irregular \\
$5-$ Vegetação arbórea & Vegetação, superior a 4 m de altura & Regular \\
6 - Solo exposto & Área de solo exposto & Irregular \\
7 - Vegetação rasteira & Com altura inferior a 0,50 m & Irregular \\
$8-$ Pavimentação asfáltica & Com cobertura impermeabilizante asfáltica & Irregular \\
$9-$ Pavimentação irregular & Com cobertura irregular (paralelepípedo) & Irregular \\
$10-$ Lago & Tanque de água, açude & Irregular \\
\hline
\end{tabular}


esse fim.

A Classe 1 - "agricultura" - foi considerada toda e qualquer área de cultivo ou preparada para

Na Classe 2 - "vegetação arbustiva" ou "capoeira", como também é chamada - há duas interpretações legais. A primeira é a de vegetação em estágio primário de recuperação, em área abandonada, sem uso e cercada para impedir o acesso de animais. Nesse caso, seria considerada regular. A segunda interpretação é a de área com uso constante, suprimindo a vegetação e impedindo a regeneração natural. Nessa situação, a área é considerada irregular. Por se tratar de área urbana, a primeira condição dificilmente ocorre, tornando-se contrária à legislação.

Classe 3 - "estradas sem pavimentação".

Classe 4 - "edificações". Nessa classe enquadram-se habitações, edículas, galpões e qualquer outra construção em madeira ou alvenaria. A interpretação legal dessa situação varia. De modo geral, a situação é irregular, porém, dependendo do período em que foi edificada a obra, devido a variações e mudanças nas leis, a situação pode ser considerada regular, mas depende de cada caso.

Classe 5 - "vegetação arbórea" -, que apresenta árvores com altura superior a $4 \mathrm{~m}$. É a única classe admitida como regularizada perante a legislação. Porém é preciso considerar vários aspectos. O primeiro diz respeito à largura da cobertura de árvores, que deve considerar toda a área de $50 \mathrm{~m}$ de raio da nascente. A não abrangência da área total torna a área irregular. O segundo aspecto diz respeito ao tipo de vegetação, sendo admitidas somente espécies nativas da região. O terceiro ponto é a regeneração, que deve estar ocorrendo naturalmente, considerando que não deve ocorrer trânsito de animais e pessoas nessas áreas.

Classe 6 - "solo exposto", sem cobertura vegetal, sem impermeabilização ou compactação para o trânsito de veículos. Essa situação é irregular perante a legislação e provoca o desencadeamento de processos erosivos.

Classe 7 - "gramíneas", vegetação típica de áreas de uso antrópico constante (campos de futebol e jardins), ou de locais que sofreram degradação em grau que não possibilite a regeneração natural. A altura varia entre grama rala até capim com $0,5 \mathrm{~m}$ de altura. As áreas englobadas nessa classe estão em conflito com a legislação CONAMA 303/02, por apresentarem uso constante ou por se tratar de locais que precisam da intervenção humana para regeneração, sendo essa responsabilidade do proprietário da área.

As classes 8 e 9 constituem-se de solo impermeabilizado, compactado ou preparado (com saibro ou pedra brita) para o trânsito de veículos. Essas classes englobam pontes e viadutos, bem como pátios de manobra de indústrias e vias de acesso. A situação somente é regular se consideradas as obras que possuem aprovação por parte do órgão ambiental, condição prevista em lei por apresentar benefício social, como é o caso de pontes e viadutos.

Classe 10 - "Lago" (tanques, açudes, lagos para recreação ou áreas represadas). Os elementos considerados nessa classe se diferenciam de nascentes ou lagos naturais, por possuírem formato retangular, condição pouco comum em ambiente natural. Encontram-se em desacordo com a legislação devido ao fato de serem obras civis. A resolução CONAMA 302/02 determina APP específica para lago ou açude, mesmo quando for construído artificialmente. A resolução CONAMA 302/02 e a situação legal dos lagos e açudes não faz parte da abordagem deste trabalho.

Após a definição das classes e sua abrangência, o processo seguinte foi associar as diferentes classes sobre o plano de informação que contém a imagem do satélite e posteriormente fazer a medição da área das classes pertencente a cada nascente.

\section{RESULTADOS E DISCUSSÃO}

\section{Área total do estudo}

O Arroio dos Pereiras, que está situado dentro da área urbana do município, possui área total de 352 ha. A extensão do curso d'água é de $7.085 \mathrm{~m}$ lineares e a largura média é de 3,5 m. Foram identificadas 28 nascentes (Figura 3), das quais 15 possuem áreas de APP coincidentes, totalizando 19 polígonos na área da bacia.

A APP de cada nascente, como descrito na legislação, deve apresentar $50 \mathrm{~m}$ de raio, o que, pela aplicação da fórmula da circunferência, resulta em uma área de $7.853 \mathrm{~m}^{2}$. Nos polígonos com área coincidente, foi efetuada a soma das áreas, sendo estabelecidas áreas maiores. A tabela 2 descreve alguns parâmetros, como localização das nascentes e a área dos polígonos das APPs na bacia. 
Tabela 2. Polígonos, coordenadas UTM e área (ha) das nascentes do Arroio dos Pereiras.

Table 2. Polygons, UTM coordinated and area (hectare) of the springs of the Pereira's Stream.

\begin{tabular}{|c|c|c|c|c|}
\hline \multirow{2}{*}{ Polígono } & \multirow{2}{*}{ Nascente } & \multicolumn{2}{|c|}{ Coordenadas (planas) } & \multirow{2}{*}{ Área $\left(m^{2}\right)$} \\
\hline & & $\mathbf{x}$ & $\mathbf{y}$ & \\
\hline 1 & 1 & 535665.5216 & 7182568.3178 & $7.853,98$ \\
\hline 2 & 2 & 536036.9185 & 7182543.2317 & $7.853,98$ \\
\hline 3 & 3 & 536409.9516 & 7182487.9833 & $7.853,98$ \\
\hline \multirow{3}{*}{4} & 4 & 536008.2926 & 7182399.8115 & \multirow{3}{*}{$16.744,08$} \\
\hline & 5 & 536002.4150 & 7182381.2019 & \\
\hline & 6 & 536001.5871 & 7182306.9530 & \\
\hline 5 & 7 & 536100.3041 & 7182220.7391 & $7.853,98$ \\
\hline 6 & 8 & 536134.4153 & 7182123.0417 & $7.853,98$ \\
\hline \multirow{3}{*}{7} & 9 & 536001.4774 & 7182162.3818 & \multirow{3}{*}{$17.671,15$} \\
\hline & 10 & 535983.6640 & 7182079.9544 & \\
\hline & 11 & 536011.2382 & 7182079.9544 & \\
\hline 8 & 12 & 535810.5052 & 7182083.6721 & $7.853,98$ \\
\hline \multirow{2}{*}{9} & 13 & 536088.1451 & 7181964.0147 & \multirow{2}{*}{$15.050,63$} \\
\hline & 14 & 536157.3007 & 7181917.3718 & \\
\hline 10 & 15 & 536333.9107 & 7181964.1556 & $7.853,98$ \\
\hline 11 & 16 & 535858.0783 & 7181889.8797 & $7.853,98$ \\
\hline 12 & 17 & 535643.6091 & 7181895.9005 & $7.853,98$ \\
\hline 13 & 18 & 536296.8943 & 7181804.9393 & $7.853,98$ \\
\hline \multirow{2}{*}{14} & 19 & 536096.8852 & 7181796.2974 & \multirow{2}{*}{$12.868,44$} \\
\hline & 20 & 536146.3690 & 7181772.9413 & \\
\hline \multirow{3}{*}{15} & 21 & 535768.0255 & 7181716.1818 & \multirow{3}{*}{$14.537,47$} \\
\hline & 22 & 535807.0845 & 7181769.3451 & \\
\hline & 23 & 535800.1105 & 7181768.4439 & \\
\hline \multirow{2}{*}{16} & 24 & 536023.8881 & 7181682.3213 & \multirow{2}{*}{$14.919,47$} \\
\hline & 25 & 536107.6880 & 7181666.0485 & \\
\hline 17 & 26 & 536321.1349 & 7181545.2267 & $7.853,98$ \\
\hline 18 & 27 & 536247.4334 & 7181446.6626 & $7.853,98$ \\
\hline 19 & 28 & 5357680723 & 7181453.6890 & $7.853,98$ \\
\hline
\end{tabular}

A área de estudo abrangida pelas APPs das nascentes somam 19,39 ha, ou seja, cerca de 5\% da área da bacia.

A classificação do uso do solo consistiu em criar polígonos fechados, em um plano de informação colocado sobre a imagem do satélite Quickbird. De acordo com a textura da imagem, foi executada a determinação de cada uso do solo, conforme a figura 3, utilizando as classes anteriormente descritas.

Ao final da classificação da área dos polígonos, obteve-se o total de área por classe, conforme mostrado na figura 3 .

Como resultado final da classificação de 19,39 ha pertencentes à APP das nascentes, foi possível constatar que $15 \%$ encontram-se com vegetação arbórea, que está distribuída por toda a área de estudo.

Os resultados obtidos sugerem que a legislação ambiental não têm sido relevante no processo de planejamento urbano da cidade em estudo, desconsiderando a premissa apresentada por Saraiva; Polidori (2006) de que as bacias e sub-bacias são as representações espaciais fundamentais no planejamento ambiental.

Esse conjunto de dados serve como base para o planejamento ambiental e para o sucesso das intervenções necessárias para a recuperação e uso sustentável dos corpos aquáticos. 


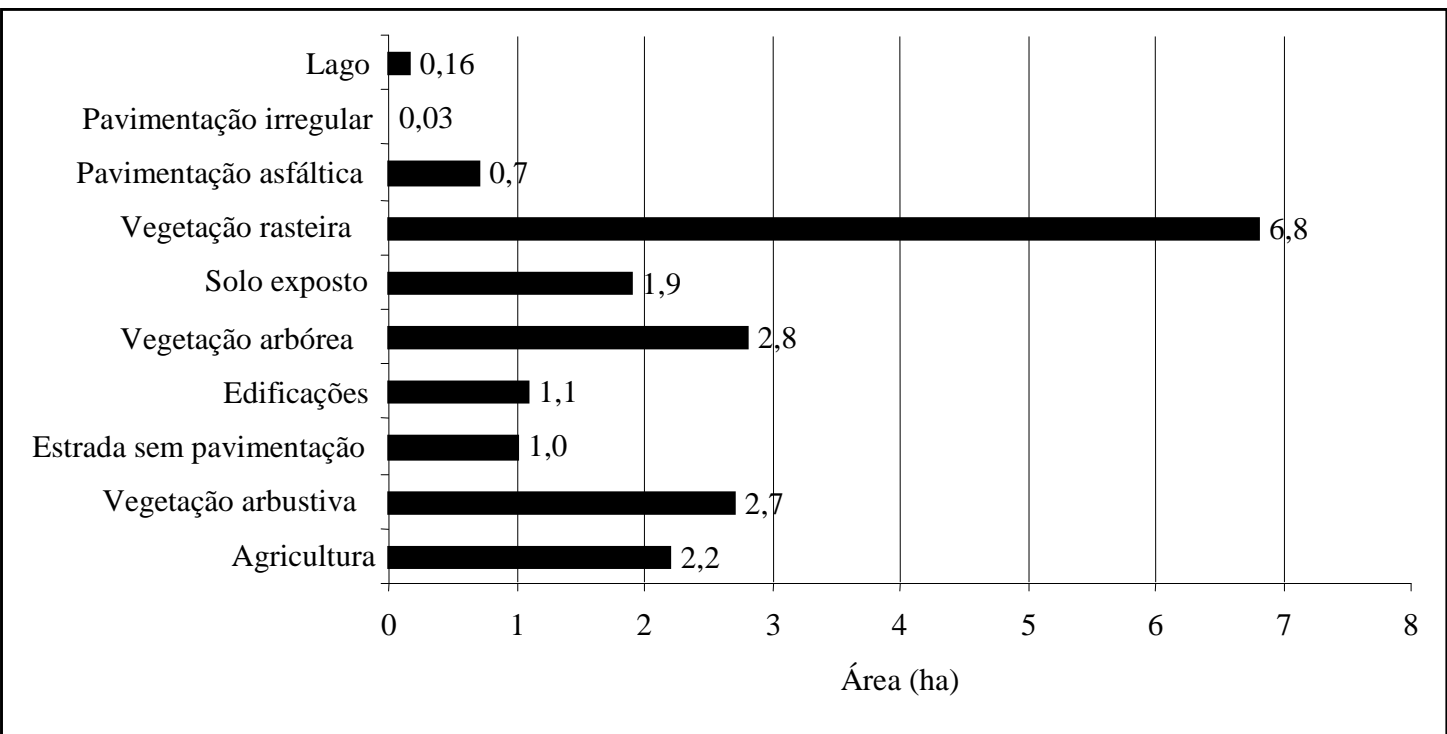

Figura 3. Área em hectares para cada situação de uso do solo, nas áreas de preservação permanente das nascentes.

Figure 3. Area in hectares by each situation of land use, in the permanent preservation areas of the springs.

\section{CONCLUSÕES}

- A legislação sobre as APPs das nascentes não está sendo respeitada na área do estudo, pois somente $15 \%$ apresentam cobertura arbórea e cerca de $85 \%$ encontram-se irregulares, devido ao uso inadequado do solo.

- De modo geral, as APPs das nascentes apresentam elevado nível de degradação ambiental, com exceção de poucas áreas isoladas de vegetação arbórea, o que confronta a legislação que define um raio de $50 \mathrm{~m}$.

- A questão da recuperação das APPs para atender à legislação é uma solução que necessita de um amplo diagnóstico, pois em alguns locais simplesmente não é possível restabelecer a condição natural, visto que existem edificações, estradas e outros elementos que impossibilitariam a recuperação.

- As imagens de alta resolução permitiram o estudo da ocupação atual do solo na área da bacia e, sobretudo, nas áreas específicas de APP das nascentes.

\section{AGRADECIMENTOS}

Os autores agradecem ao apoio da Prefeitura Municipal de Irati, através de seu Departamento de Geoprocessamento, pela cessão das imagens de satélite.

\section{REFERÊNCIAS}

ANEEL - AGÊNCIA NACIONAL DE ENERGIA ELÉTRICA. Bacias Hidrográficas do Brasil. Disponível em: <http://www.aneel.gov.br/104.htm>. Acesso em: 10/08/2007.

BRASIL. Lei ${ }^{\circ}$ 4.771, de 15 de setembro de 1965. Institui o novo código florestal. Diário Oficial da União, Brasília, DF, 16 de setembro de 1965. Disponível em: <http://www.planalto.gov.br/ccivil_03/Leis/L4771.htm>. Acesso em: 10/08/2007. 
CAMARA G; SOUZA, R.C.M.; FREITAS, U.M, GARRIDO. J. SPRING: integrating remote sensing and GIS by object-oriented data modelling. Computers \& Graphics, New York, v. 20, n.3, p. 395-403, MayJun 1996.

CONAMA - CONSELHO NACIONAL DE MEIO AMBIENTE (Brasil). Resolução no 303, de 20 de março de 2002. Dispõe sobre parâmetros, definições e limites de Áreas de Preservação Permanente. Diário Oficial da União, Brasília, DF, 13 de maio de 2002. Disponível em: <http://www.mma.gov.br/port/conama/res/res02/res30302.html>. Acesso em: 10/08/2007.

EMBRAPA - EMPRESA BRASILEIRA DE PESQUISA AGROPECUÁRIA. Disponível em: <http://www.sat.cnpm.embrapa.br/satelite/quickbird.html>. Acesso em: 13/10/2007.

JANSEN, J. R.; COWEN, D. C. Remote sensing of urban/suburban infrastruture and socioeconomic attributes. Photogrammetric Engineering and Remote Sensing, Falls Church, v. 65, n. 5, pp. 611-622, 1999.

IRATI. Disponível em: <http://www.irati.pr.gov.br/municipio/localizacaogeografica>. Acesso em: $10 / 08 / 2007$.

NAGHETTINI, M. (2006) A bacia hidrográfica. Disponível em: <www.etg.ufmg.br/tim1/bacia20hidrografica.doc>. Acesso em: 05/09/2007.

SANEPAR - COMPANHIA DE SANEAMENTO DO PARANÁ. Manual para elaboração de plano de manejo e gestão de bacia de mananciais do Estado do Paraná. 2. ed. Curitiba, 1999.

SARAIVA, M. V. P.; POLIDORI, M. C. Bacias Urbanas: O Caso de Pelotas / RS. ENCONTRO DE PÓS-GRADUAÇÃO, 9., 2007, Pelotas. Anais... Pelotas: UFPe. Faculdade de Agronomia Eliseu Maciel, 2007. 1 CD-ROM.

SILVA, B. A. W.; AZEVEDO, M. A.; MATOS, J. S. Gestão ambiental de bacias hidrográficas urbana. Revista VeraCidade, Salvador, Ano 1, n. 1, dez., 2006. Disponível em: < http://www.veracidade.salvador.ba.gov.br/v1/images/veracidade/pdf/artigo2.pdf>. Acesso em: 05/09/2007.

VALÉRIO FILHO, M.; KURKDJIAN, M. L. N. O.; PEREIRA, M. N.; ALVES, M. Geotecnologias Aplicadas ao Estudo de Bacias Hidrográficas Urbanizadas Como Subsídios ao Plano Diretor de Drenagem. SIMPÓSIO BRASILEIRO DE SENSORIAMENTO REMOTO, 12., 2005, Goiânia. Anais... São José dos Campos: INPE, 2005. p. 3919-3926. 